PREPARED FOR THE U.S. DEPARTMENT OF ENERGY, UNDER CONTRACT DE-AC02-76CH03073

PPPL-3634

PPPL-3634

UC-70

Effects of Segmented Electrode in

Hall Current Plasma Thrusters

by

Y. Raitses, M. Keidar, D. Staack, and N.J. Fisch

December 2001

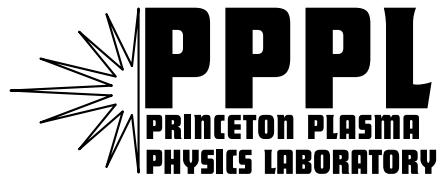

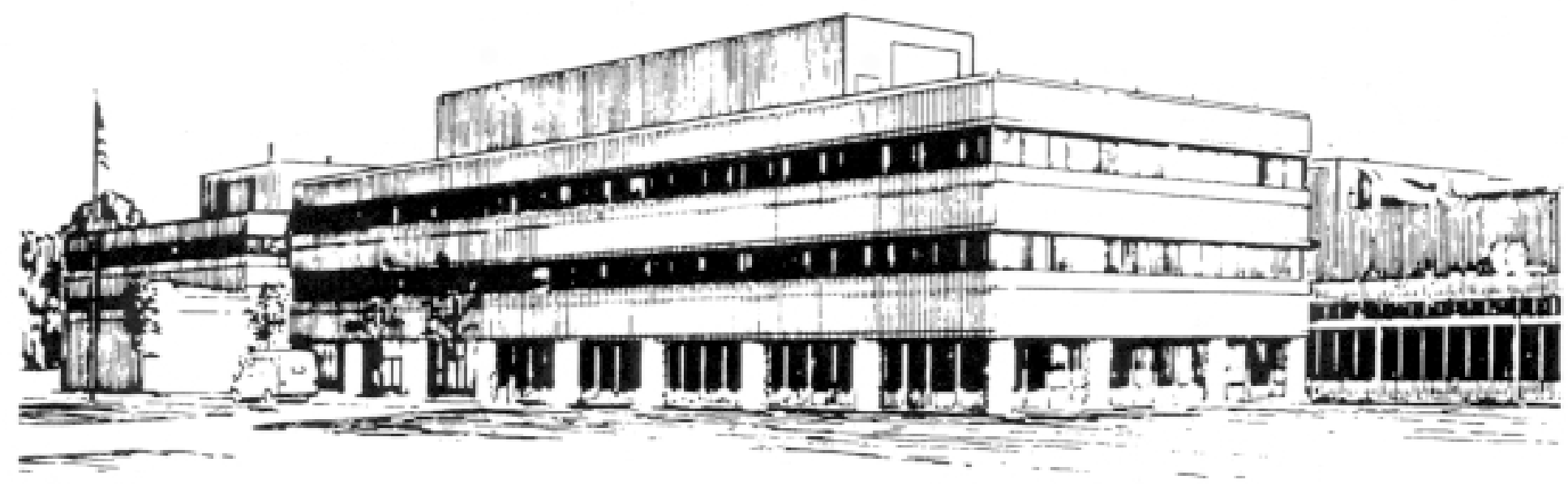

PRINCETON PLASMA PHYSICS LABORATORY PRINCETON UNIVERSITY, PRINCETON, NEW JERSEY 


\section{PPPL Reports Disclaimer}

This report was prepared as an account of work sponsored by an agency of the United States Government. Neither the United States Government nor any agency thereof, nor any of their employees, makes any warranty, express or implied, or assumes any legal liability or responsibility for the accuracy, completeness, or usefulness of any information, apparatus, product, or process disclosed, or represents that its use would not infringe privately owned rights. Reference herein to any specific commercial product, process, or service by trade name, trademark, manufacturer, or otherwise, does not necessarily constitute or imply its endorsement, recommendation, or favoring by the United States Government or any agency thereof. The views and opinions of authors expressed herein do not necessarily state or reflect those of the United States Government or any agency thereof.

\section{Availability}

This report is posted on the U.S. Department of Energy's Princeton Plasma Physics Laboratory Publications and Reports web site in Fiscal Year 2002. The home page for PPPL Reports and Publications is: http://www.pppl.gov/pub_report/

DOE and DOE Contractors can obtain copies of this report from:

U.S. Department of Energy

Office of Scientific and Technical Information

DOE Technical Information Services (DTIS)

P.O. Box 62

Oak Ridge, TN 37831

Telephone: (865) 576-8401

Fax: (865) 576-5728

Email: reports@adonis.osti.gov

This report is available to the general public from:

National Technical Information Service

U.S. Department of Commerce

5285 Port Royal Road

Springfield, VA 22161

Telephone: 1-800-553-6847 or

(703) 605-6000

Fax: (703) 321-8547

Internet: http://www.ntis.gov/ordering.htm 


\title{
Effects of segmented electrode in Hall Current Plasma Thrusters
}

\author{
Y. Raitses ${ }^{1}$, M. Keidar ${ }^{2}$, D. Staack ${ }^{1}$ and N. J. Fisch ${ }^{1}$ \\ ${ }^{1}$ Princeton University Plasma Physics Laboratory, P. O. Box 451, Princeton, NJ 08543 \\ 2 Aerospace Engineering, University of Michigan, Ann Arbor MI 48109
}

\begin{abstract}
Segmented electrodes with a low secondary electron emission are shown to alter significantly plasma flow in ceramic channel of Hall thruster. The location of the axial acceleration region relative to the magnetic field can be moved. The radial potential distribution can also be altered near the channel walls. A hydrodynamic model shows that these effects are consistent with a lower secondary electron emission of the segmented electrode as compared to ceramic channel walls.
\end{abstract}




\section{Introduction}

A conventional Hall current plasma thruster is a crossed field discharge device with a coaxial channel, in which the electrostatic acceleration of ions takes place in quasineutral plasma. A significant axial electric field is established in the vicinity of the maximum radial magnetic field, typically near the thruster exit. Thruster performance, namely, jet velocity, acceleration efficiency and beam divergence are strongly affected by the location of the acceleration region and therefore by the location of main axial electric field. The length of the acceleration region and its location relative to the magnetic field distribution depends mainly on the electron mobility and can be strongly affected by material properties of the channel walls and plasma-wall interaction. ${ }^{1-5}$ Generally speaking, a simple exchange of the channel materials, for example, from ceramic to metal, may lead to a different acceleration regime or at least to a different spatial distribution of plasma properties in the channel ${ }^{2,3,5}$, even if not necessarily to changes in thruster performance. A possible reason for the thruster performance being similar is that at a given discharge voltage a change in material properties of the entire channel walls, namely the secondary electron emission (SEE) and conductivity, causes a change in the ion flux to the walls, which is balanced by a change in a length of the acceleration region. As a result, there are no substantial differences of the ion wall losses and thus, the integral characteristics of the thruster., ${ }^{2,3}$

The conventional Hall thruster channel is made entirely from either ceramic or metal. However, in a segmented electrode Hall thruster, metal electrodes are placed along the 
ceramic channel. It was shown in Refs. 6 and 7 that a Hall thruster of single and multi segmented electrode configurations was able to reduce the exhaust plasma plume angle by about $20 \%$ compared to a conventional non-segmented thruster configuration. The mechanism that leads to the plume narrowing, as well as to the generally large plume angle $\left(\sim 90^{\circ}\right)$ for Hall thrusters in the first place is not clear yet. The object of the present study is to examine in detail how the plasma responds to the presence of a segmented electrode in the ceramic channel.

This paper is organized as following: The experimental set-up and results are described in Section I. Section II devoted to the description of the theoretical approach and important results of the simulation. In Section III we compare and discuss the measured and predicted results.

\section{Experimental setup and results}

The $9 \mathrm{~cm}$ laboratory Hall thruster and test facility used in this study has been described in detail in Refs. 6 and 7. Fig. 1 shows this thruster with a 4 mm length segmented electrode placed on the inner wall near the exit of the channel, which is made from boron nitride ceramic. The segmented electrode is made from low sputtering carbon-carbon-fiber graphite material. The placement of the electrode relative to the magnetic field distribution is shown in Fig. 2. As shown in Ref. 6, this placement of a single segmented electrode corresponds to the most substantial reduction of the plume angle. 
In these experiments, we used a fast movable emissive probe setup to measure the plasma potential distribution inside the thruster channel (Fig. 1). The floating potential of the probe relative to the ground was measured using a 1:100 isolating amplifier and monitored by a PC-based data acquisition system. The details of the emissive probe setup are described in Ref. 8 . In the present experiments, the residence time of the probe inside the channel was shorter than $0.3 \mathrm{sec}$. The probe position relative to the thruster channel was measured by a Rensishaw optical encoder with 20-micron resolution. Control and measurement of this positioning system is performed by a PC-based data acquisition system. Other measurements included mass flow rate, discharge current and voltage, electromagnetic coils current. The thruster electrodes were floating relative to the ground.

The following procedure for the probe measurements was followed: After the thruster operation reached steady state, the fast probe was introduced into the channel first near its outer wall with no heating, and then with gradually increased heating. At operational heating power, the probe reached saturation values of its floating potential along its trajectory. Keeping this power constant, the probe measurements were repeated several times to characterize reproducibility and estimate average profiles. Next, the probe position was changed in the radial direction and the procedure was repeated. In both thruster configurations, potential profiles were measured for 9 radial positions of the probe. Reproducibility of probe measurements was greater than $85 \%$. The major source of irreproducibility was probe-induced perturbations of the thruster discharge, which tended to increase and then saturate as the probe moved toward the anode (Fig. 3). The amplitude of the discharge current perturbations could reach $50 \%$ of its steady state 
value. These perturbations appear less than $0.1 \mathrm{sec}$ after the probe immersion and are more substantial at the channel median than near the outer and inner walls. Therefore, it is not clear if they result from probe heating and ablation by electron Hall current. ${ }^{9}$ In addition to these perturbations, uncertainties of the emissive probe measurements include a voltage drop across the filament produced by the dc heating power supply $(\sim 10 \mathrm{~V})$ and a double sheath formed between the hot floating probe and plasma $\left(\Delta \varphi \approx T_{e}\right) .{ }^{10}$

Despite uncertainties due to probe-induced perturbations of the plasma, in the region near the thruster exit plane and outside the thruster, these perturbations are not so appreciable. Therefore, while comparing the measured results, we shall concentrate on this region. Fig. 4 shows equipotential counter lines derived from measurements for segmented and non-segmented thruster configurations. These results were measured at the same operating conditions: discharge voltage of $250 \mathrm{~V}$ and Xenon gas mass flow rate of 1.7 $\mathrm{mg} / \mathrm{s}$. The magnetic field was also constant. Remarkably, the location of the acceleration and ionization region relative to the magnetic field distribution is substantially affected by the segmented electrode. It moves a few millimeters upstream of the channel, as compared to non-segmented thruster configuration. As a result, there is a relatively smaller fraction of the voltage drop left outside the thruster channel in the fringing magnetic field. In the conventional configuration, about $40-50 \%$ of the measured voltage drop is outside the thruster channel. As can be seen from the model described below, this effect of the segmented electrode can be partially attributed to the dependence of the plasma flow on the SEE of the wall materials. 


\section{Model of the plasma flow in the Hall thruster with segmented electrode}

In this section we describe the model of the plasma flow in a cylindrical channel as shown in Fig. 2. The plasma flow starts in the near anode region and has the lateral boundaries near the dielectric wall. The plasma presheath-sheath interface is considered to be the lateral boundary for the plasma flow region. The entire quasi-neutral plasma region is considered as a presheath in which the boundary conditions for the sheath entrance are developed. Details of the model of the plasma-sheath transition region are described elsewhere ${ }^{3}$. The sheath region in front of the dielectric surface is considered to be collisionless. The dielectric wall effect is taken into account by introducing an effective coefficient of SEE, $s$. Sectioned metal electrode is introduced in the model as a region with smaller SEE as shown in Fig. 2.

A plasma is considered with 'magnetized' electrons and 'unmagnetized' ions, i.e. $\rho_{\mathrm{e}}<<\mathrm{H}<<\rho_{\mathrm{i}}$, where $\rho_{\mathrm{e}}$ and $\rho_{\mathrm{i}}$ are the Larmor radii for the electrons and ions respectively, and $\mathrm{H}$ is the channel characteristic length. It is assumed that the magnetic field has only a radial component. Cylindrical coordinates will be used, as shown in Fig. 2, with angle $\theta$, radius $\mathrm{r}$, and axial distance from the anode $\mathrm{z}$, respectively. A hydrodynamic model is employed in a 2-D domain assuming that the system reaches a steady state. The momentum and mass conservation equations for electrons, ions and neutrals under these conditions have the following form:

$\mathrm{nm}_{\mathrm{i}}\left(\mathrm{V}_{\mathrm{i}} \nabla\right) \mathrm{V}_{\mathrm{i}}=\mathrm{neE}-\nabla \mathrm{P}_{\mathrm{i}}-\beta \mathrm{nm}_{\mathrm{i}} \mathrm{n}_{\mathrm{a}} \mathrm{V}_{\mathrm{a}}$ 
$0=-e n(E+V \times B)-\nabla P_{e}-n v_{e f} m_{e} V_{e}$

$\nabla \cdot\left(\mathrm{V}_{\mathrm{i}} \mathrm{n}\right)=\beta \mathrm{nn}_{\mathrm{a}}$

$\nabla \cdot\left(\mathrm{V}_{\mathrm{a}} \mathrm{n}_{\mathrm{a}}\right)=-\beta \mathrm{nn}_{\mathrm{a}}$

where $\mathrm{i}, \mathrm{a}$, e are subs for ions, neutral atoms and electrons, respectively, $\mathrm{n}$ is the plasma density, $\beta$ is the ionization rate, $\mathrm{V}$ is the velocity, $v_{\mathrm{ef}}$ is the effective collision frequency.

In order to simplify the problem, yet including the major physical effects, we consider one-dimensional flow of the neutrals. Since only the radial magnetic field component is considered in the model, the electron transport is greater in the azimuthal direction $(\mathrm{E} \times \mathrm{B}$ drift) than in the axial direction (drift diffusion due to collisions). Electrons can freely move along magnetic field lines and therefore the electric field potential is constant along magnetic field lines within accuracy of the electron pressure gradient. If we assume that the electron temperature is constant along each magnetic field line we obtain

$\varphi-\frac{\mathrm{kT}_{\mathrm{e}}}{\mathrm{e}} \ln (\mathrm{n})=\mathrm{const}$

The left-hand side of this equation is known as a thermalized potential ${ }^{1}$. This equation makes it possible to reduce the two-dimensional calculation of the electric field to a onedimensional problem in the way similarly to Refs. 3,11,12. Calculating the potential distribution along the channel centerline makes it possible to calculate the potential in the entire domain. The electron temperature is calculated along the centerline as a balance 
between the Joule heating, ionization and wall losses as described elsewhere ${ }^{3,11}$. In this model we consider that electron transport across the magnetic field is due several collision mechanisms: electron-neutral collisions, electron-wall collisions and anomalous (Bohm) diffusion: $v_{\mathrm{ef}}=v_{\mathrm{en}}+v_{\mathrm{ew}}+v_{\mathrm{B}}$, where $v_{\mathrm{ef}}$ is the effective electron collision frequency.

At the upstream boundary (anode plane, $\mathrm{z}=0$, see Fig. 1 ) we specify the density and velocity similarly to Ref. 1 assuming that the ion velocity $\mathrm{V}_{\mathrm{o}}=2 \times 10^{3} \mathrm{~m} / \mathrm{s}$ near the anode that corresponds to $3 \mathrm{eV}$. This upstream condition implies that we are considering only supersonic plasma flow assuming that the transition from the subsonic to supersonic flow occurs in the anode vicinity. The atom velocity near the anode is assumed to be $\mathrm{V}_{\mathrm{oa}}=2 \times 10^{2} \mathrm{~m} / \mathrm{s}$ (Ref. 13). At the downstream boundary (thruster exit plane, $\mathrm{z}=\mathrm{L}$ ), we specify electron temperature, assuming, similarly to Ref. 13 , that $T_{e}=5 \mathrm{eV}$ which is close to that measured in experiment ${ }^{14}$. Results are presented for the following conditions: Discharge current: 1.65 A (segmented electrode thruster case) and 1.6 A (conventional thruster case), anode mass flow rate: $1.7 \mathrm{mg} / \mathrm{s}$. We used the magnetic field axial profile corresponding to the measured value along the centerline of the channel.

The numerical analysis is similar to that developed previously ${ }^{15}$. We use the implicit twolayer method to solve the system of equations (1)-(4). These equations are approximated by a two-layer six point scheme. The electron temperature distribution in axial direction is calculated by iteration. More details about this model and numerical solution can be found in Ref. 3. 
Calculated propellant utilization at the thruster exit plane, $x=L$, is shown in Fig. 5. For comparison the measured propellant utilization is also shown ${ }^{6}$. One can see that the magnitude as well as general trend predicted by the model is close to that observed experimentally. It should be noted that the same agreement was obtained for the thrust.

Axial distribution of the electron temperature is shown in Fig. 6. It can be seen that the electron temperature is higher in the case of the channel with segmented electrode and peaks at about $18 \mathrm{eV}$ in the acceleration region near the channel exit (the peak corresponds to the segmented electrode position).

The potential distribution along the channel centerline for two thruster configurations is shown in Fig. 7. In these calculations we employed the experimental fact (Refs. 6,7) that the discharge is higher in the case of the thruster operated with segmented electrode.

\section{Discussion}

We shall now discuss and compare our model prediction of plasma potential distribution with experimental results. We will focus on two major experimentally observed effects, the inward shift of the plasma potential distribution and the unexpected plasma potential structure in the radial direction for segmented electrode thruster case as compared to conventional case (Fig.4). 
Both the experimental results and the numerical simulation show a shift in the acceleration region towards the anode (Figs. 4 and 7). However the magnitude of the shift in the model is less than the measured shift. Possible reasons for the discrepancy could be both experimental and theoretical. For example, the probe-induced perturbations of the plasma potential could be different in the segmented electrode configuration than in the conventional thruster. Though the perturbations to the discharge current were similar in both thruster configurations. On the other hand the theoretical model does not take into account the 2D configuration of the magnetic field nor does it take into account ion collecting role of the electrode. Additionally, the model employs local balance of the ion and electron fluxes to the wall while in reality the only global balance of the ion and electron fluxes (i.e. integrated over the length of the electrode) is taken place.

In the present model we assumed that the electron temperature is constant in the radial direction, i.e., along magnetic field lines, and therefore the axial distribution of the electron temperature shown in Fig. 6 has the meaning of some average $T_{e}$ in the channel cross section. However, in reality, the electron temperature field in the Hall thruster channel is rather two-dimensional. Following results of Fig.6 and taking in to account that metals have typically smaller SEE than ceramics at the same energy of primary electrons, one can expect that the electron temperature will be higher near the graphite segment placed in the boron nitride channel. On the other hand, there is no segmented electrode on the opposite side of the channel (See Fig. 2). As a result, the presence of the segmented electrode only on one side of the channel may create an electron temperature gradient in radial direction and lead to electron current along the magnetic field lines, $\mathrm{je}_{\mathrm{e}}$. 
Then, current conservation implies that the electron current in the axial direction near the ceramic wall opposite to the segmented electrode must increase. Using the plasma parameter distribution from our 2D fluid simulation, a possible potential distribution near the outer wall can be calculated assuming that the current density there is higher than that in the middle of the channel. In this case, the potential distribution depends on the parameter $\alpha$, which is defined as ratio of the axial electron current density near the wall to the axial electron current density along the midway. Illustrative results of these calculations for different $\alpha$ are shown in Fig. 8. Here we assumed that the potential distribution in the radial direction at the thruster exit plane $(\mathrm{z}=\mathrm{L})$ is uniform. As can be seen, higher current density leads to steeper potential distribution.

Note, that a non-uniform distribution of the axial electron current density in the radial direction may be responsible for unusual concave shape of equipotentials measured for the segmented electrode case (Fig. 4). Indeed, Fig. 9 compares measured and calculated potential profiles along the channel median and near the outer wall. Assuming electron current density near the outer wall higher than the axial electron current density at the middle we can get a qualitative agreement between theory and experiment. In addition, these theoretical predictions are also supported by the results measured with the second segmented electrode placed on the outer wall of the ceramic channel, opposite to the inner segmented electrode (Fig. 10). In this two-segmented thruster case, no concave shape of equipotential was observed and the measured plasma potential changes are insignificant in the radial direction as compared to the single segmented electrode configuration of Fig. 4. These results suggest that electron temperature gradient in radial 
direction may be responsible for developing unusual concave shape of equipotentials observed in these experiments with single segmented electrode.

\section{Concluding remarks}

A segmented electrode Hall thruster channel leads to some interesting phenomena measured experimentally and partially explained by a hydrodynamic plasma model. Two major effects of the segmented electrode include the inward shift of the acceleration region and the changes in the shape of equipotentials. These effects might be due to a lower secondary electron emission of the segmented electrode as compared to ceramic channel walls. Therefore, the shape of equipotentials should depend strongly on physical properties of the channel materials, in particular, at intersections of the magnetic field lines with the outer and inner channel walls. On the other hand, an ion collecting role of the segmented electrode, which was not considered in the present model, might also contribute to these effects.

It is interesting to note that these results were obtained using only passive segmented electrodes, i.e., without electron emission and no bias. Such passive electrodes were proved to be an important tool for control plasma potential distribution in the Hall thruster channel. In addition, the model predicts and our recent experimental results have indicated, that use of segmented rings made from ceramic materials with different SEE properties instead of metal electrodes can also affect the plasma potential distribution (see for example Ref.16). On the other hand, the differences of SEE between metals and boron nitride ceramic are more substantial than between ceramics suitable for harsh 
thruster operating conditions. Therefore, it seems that segmented electrodes are still preferable tool for control of plasma potential distribution.

\section{Acknowledgement}

The authors wish to thank L. Dorf and A. Litvak for fruitful discussions and help with experiments. This work was supported by grants from the US Department of Energy under contract DE-AC02-76-CHO3073 and New Jersey Science and Technology Commission. 


\section{References}

${ }^{1}$ A. I. Morozov and V. V. Savelyev, in Review of Plasma Physics, edited by B.B.

Kadomtsev and V. D. Shafranov, Consultants Bureau, New York, Vol. 21, 2000, p. 203

${ }^{2}$ V. V. Egorov, V. Kim, A. A. Semenov and I. I. Shkarban, in Ion Injectors and Plasma Accelerators, Energoizdat, Moscow, 1990, p. 56 [in Russian]

${ }^{3}$ M. Keidar, I.D. Boyd and I.I. Beilis, Phys. Plasmas, 9 (2002)

${ }^{4}$ A. Fruchtman, N. J. Fisch and Y. Raitses, Phys. Plasmas, 8, 1048, 2001

${ }^{5}$ E. Y. Choueiri, Physics of Plasmas, 8, 5025 (2001)

${ }^{6}$ Y. Raitses, L. A. Dorf, A. A. Litvak and N. J. Fisch, J. Appl. Phys. 88, 1263 (2000)

${ }^{7}$ N. Fisch, Y. Raitses, L. A. Dorf and A. A. Litvak, J. Appl. Phys. 89, 2040 (2001)

${ }^{8}$ Y. Raitses and N. J. Fisch, Phys. Plasmas, 8, 2579 (2001)

${ }^{9}$ J. M. Haas and A. D. Gallimore, Rev. Sci. Instrum, 71, 4131, (2000)

${ }^{10}$ 13. V. A. Rozhansky and L. D. Tsendin, Transport Phenomena in Partially Ionized Gases, Gordon and Breach, Amsterdam, 2000, Chap. 3

${ }^{11}$ M. J. Fife and M. Martinez-Sanchez, $24^{\text {th }}$ Inter. Conf. Electric Propulsion, Moscow, Russia, IEPC Paper 95-240, 1995

${ }^{12}$ I. D. Boyd, L. Garrigues, J. Koo and M. Keidar, $36^{\text {th }}$ AIAA Joint Prop. Conference, Huntsville, AL, 2000, Paper AIAA-2000-3520

${ }^{13}$ J. P. Bouef and L. Garrigues, J. Appl. Phys., 84, 3541, (1998) 
${ }^{14}$ S. Kim, J.E. Foster, and A.D. Gallimore, AIAA Paper-96-2972, July 1996

${ }^{15}$ M. Keidar, I. Beilis, RL. Boxman and S. Goldsmith, J. Phys. D: Appl. Phys., 29, 1973 (1996)

${ }^{16}$ Y. Raitses, D. Staack, N. J. Fisch and M. Keidar, KP1-60, Bulletin of the $43^{\text {rd }}$ APSDPP, Long Beach, CA (2001). 


\section{Figure Captions}

Figure 1: Segmented electrode Hall thruster and probe setup

Figure 2: Magnetic field distribution, placement of the graphite segmented electrode and coordinate system.

Figure 3: Probe floating potential and discharge current measured during probe insertion along the channel median.

Figure 4: Plasma potential distribution measured relative to the ground for nonsegmented (a) and segmented thruster configurations at the same operating conditions (b). The channel exit is at $46 \mathrm{~mm}$. The inner wall at $\mathrm{R}_{\mathrm{in}}=27 \mathrm{~mm}$ and outer wall at $\mathrm{R}_{\mathrm{ot}}=$ $45 \mathrm{~mm}$.

Figure 5: Calculated propellant utilization at the thruster exit plane and comparison with measurements.

Figure 6: Calculated axial distribution of the electron temperature.

Figure 7: Calculated potential distribution along the channel median for two thruster configurations. 
Figure 8: Calculated plasma potential profiles for different ratios of the axial electron current.

Figure 9: Measured and calculated potential profiles along the channel median and outer wall for the segmented electrode case.

Figure 10: Plasma potential distribution measured for two-segmented thruster configuration. An additional $8 \mathrm{~mm}$ length segmented electrode is placed on the outer wall near the exit opposite to the inner segmented electrode. 


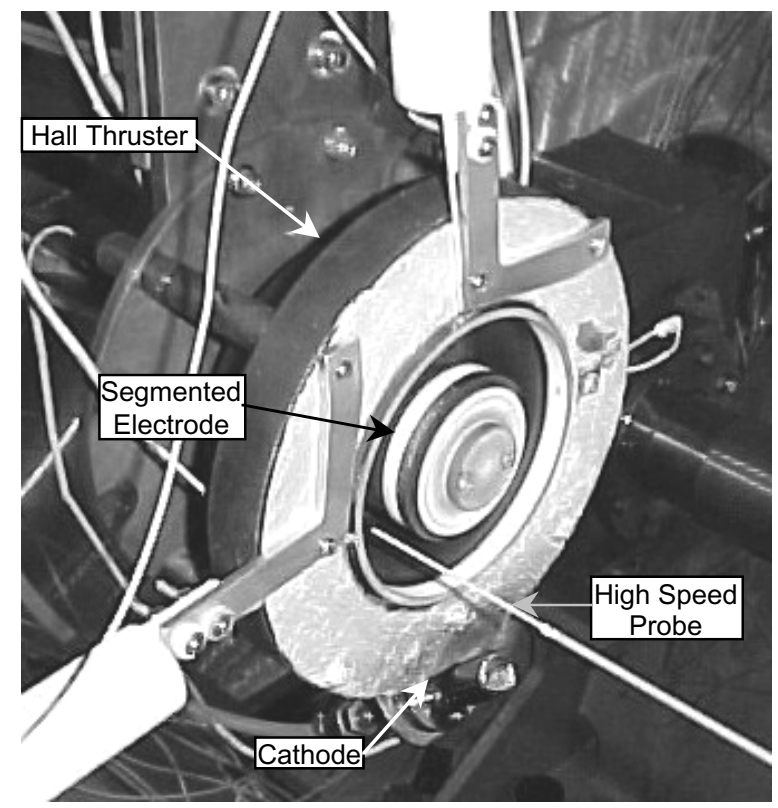

Figure 1: Segmented electrode Hall thruster and probe setup. 


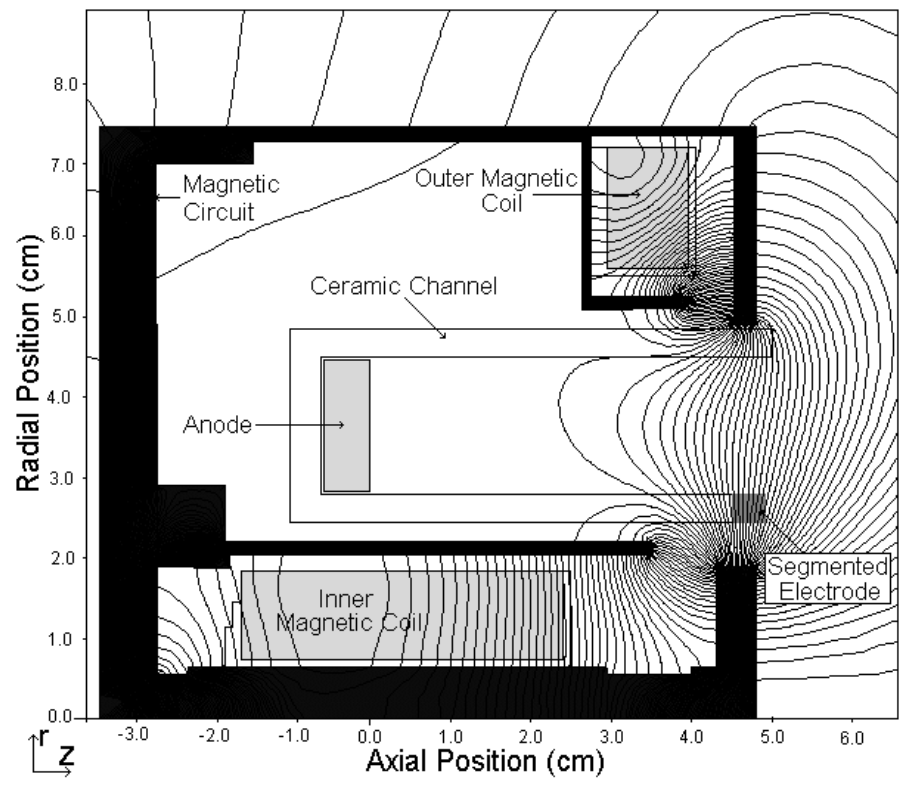

Figure 2: Magnetic field distribution and placement of the segmented electrode. 


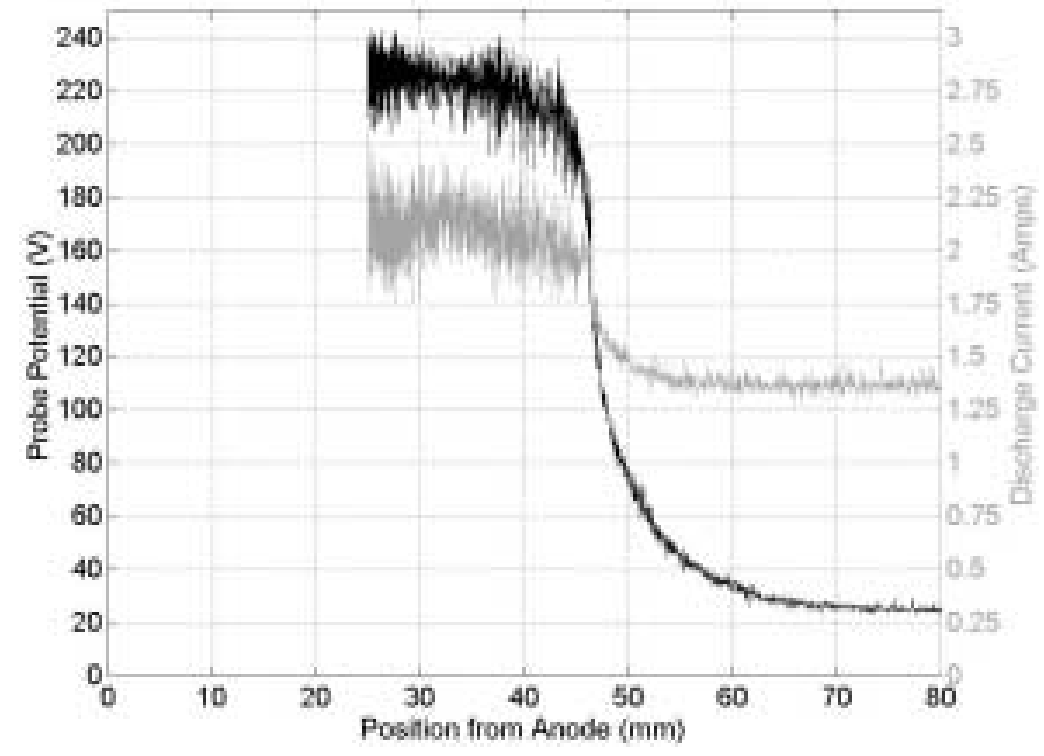

Figure 3: Probe floating potential and discharge current measured during probe insertion along the channel median. 
(a)

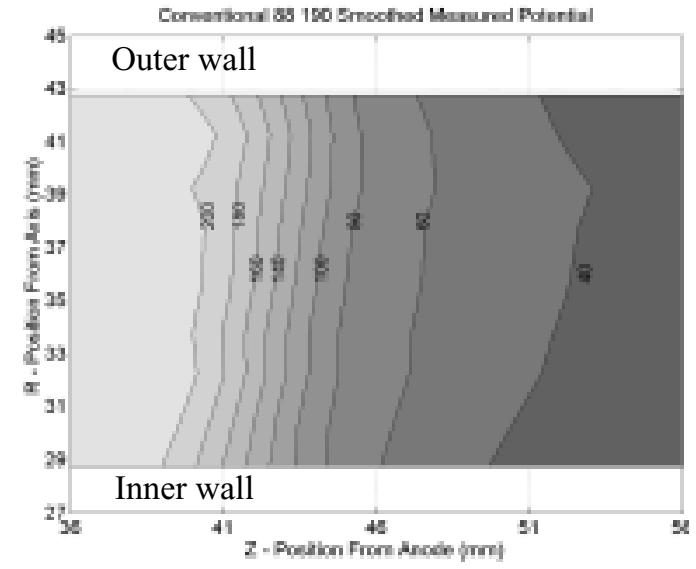

(b)

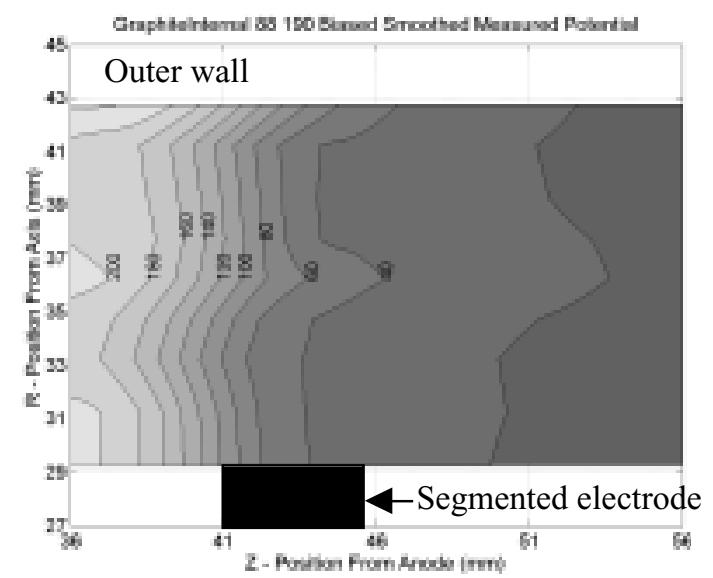

Figure 4: Plasma potential distribution measured relative to the ground for non-segmented (a) and segmented thruster configurations at the same operating conditions (b).

The channel exit at $46 \mathrm{~mm}$. The inner wall at $R_{\text {in }}=27 \mathrm{~mm}$ and outer wall at $R_{o t}=45 \mathrm{~mm}$. 


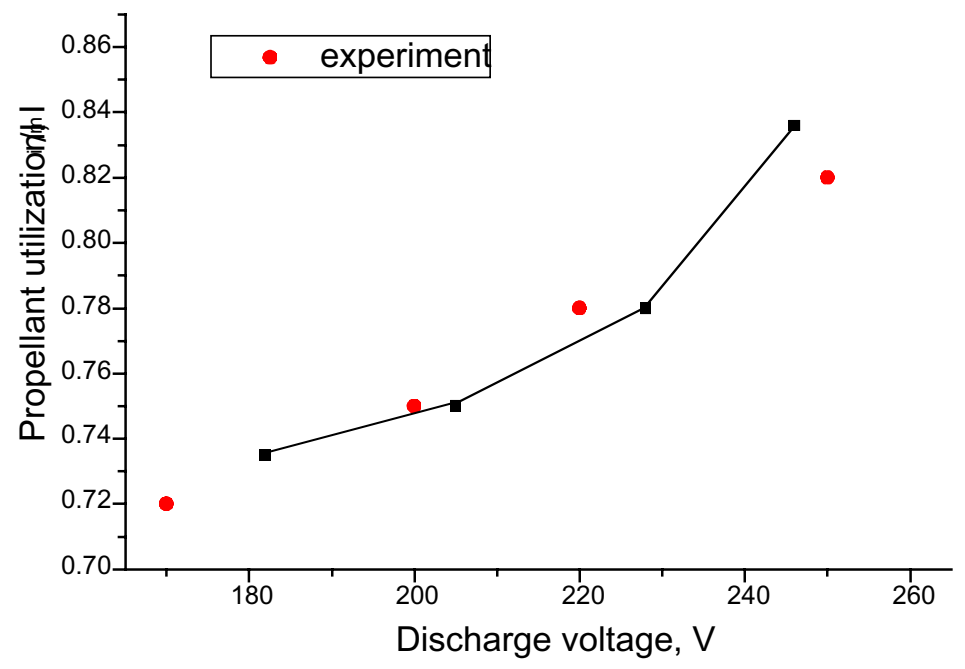

Figure 5: Calculated propellant utilization at the thruster exit plane. 


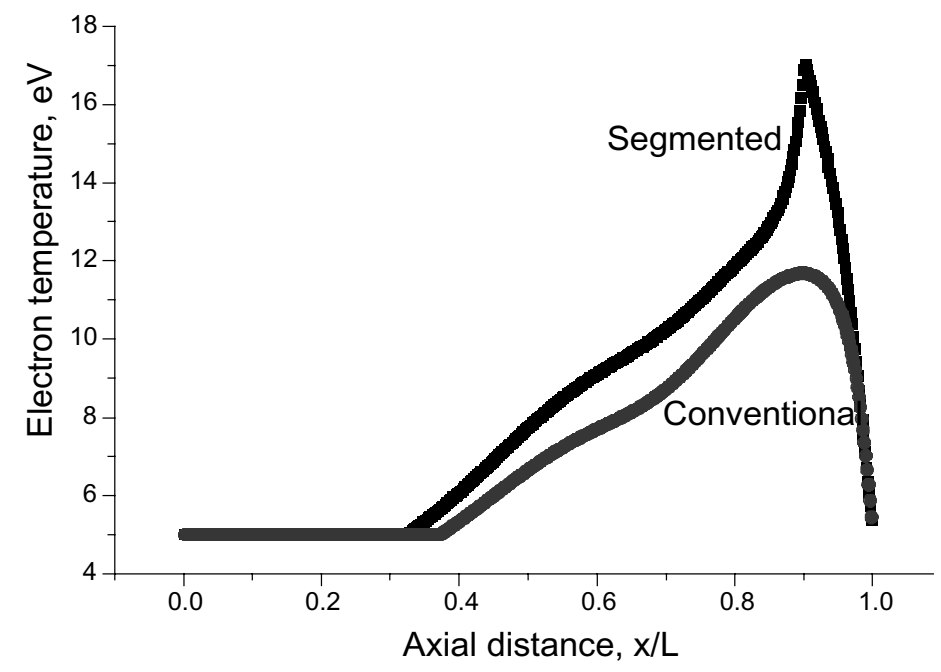

Figure 6: Calculated axial distribution of the electron temperature. 


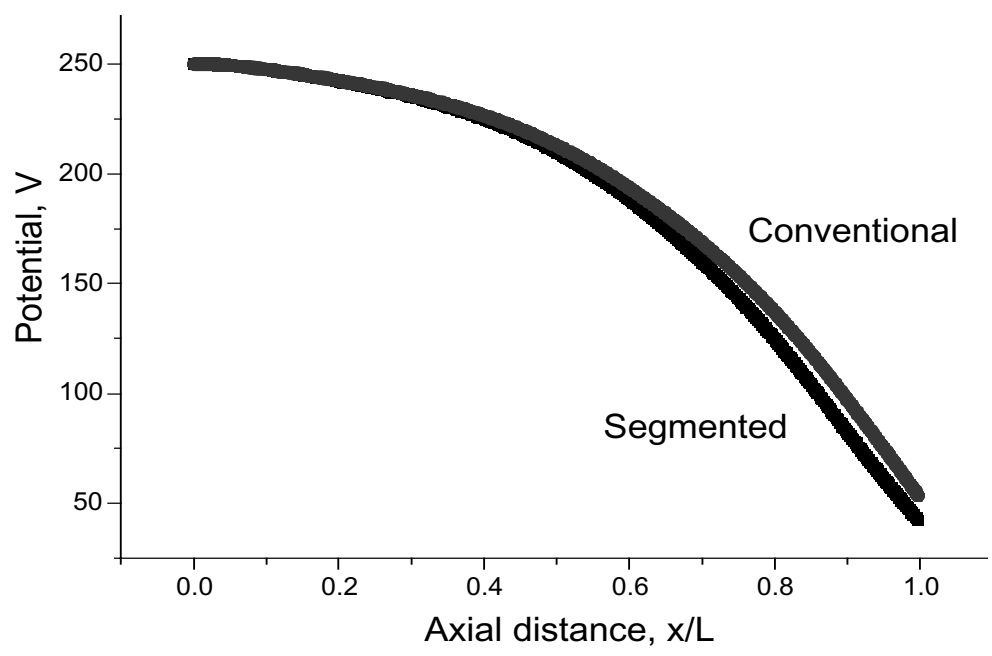

Figure 7: Calculated potential distribution along the channel median for two thruster configurations. 


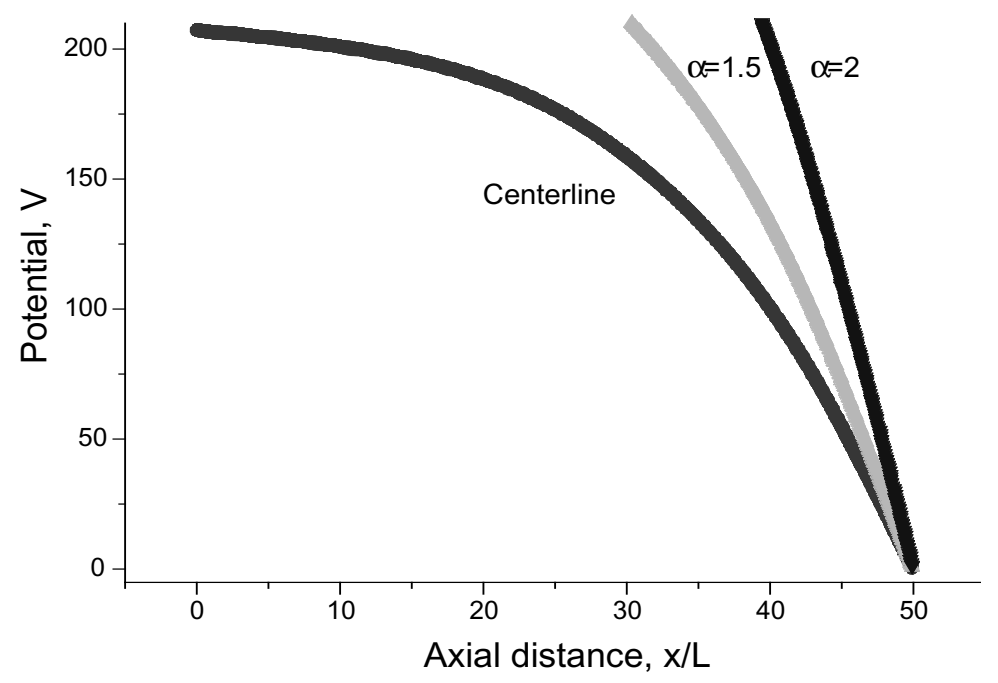

Figure 8: Calculation pf plasma potential profiles for different ratios of the axial electron current. 


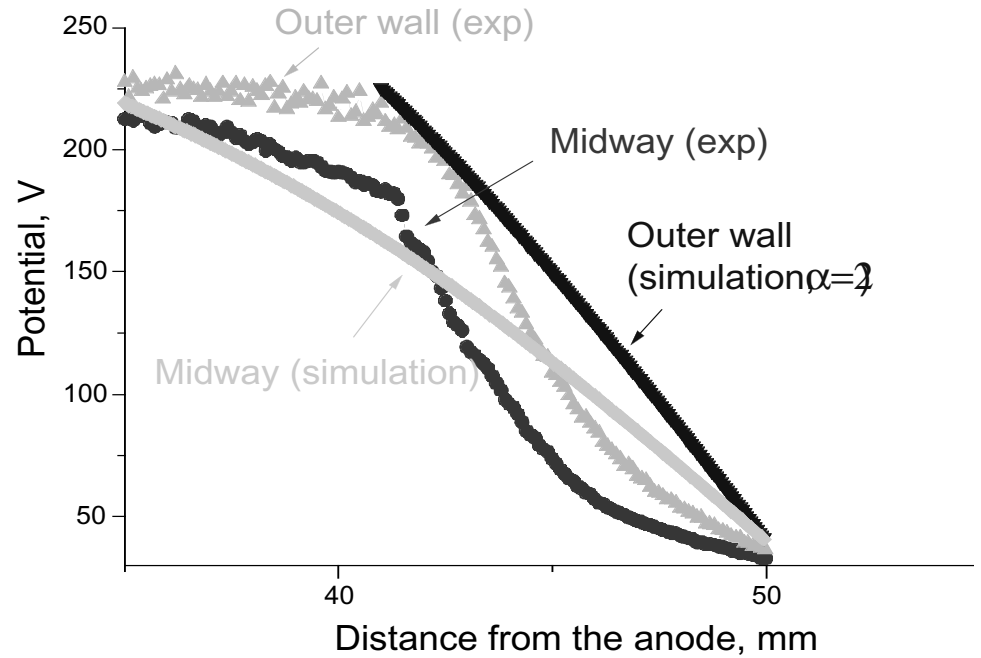

Figure 9: Measured and calculated potential profiles along the channel median and outer wall for the segmented electrode case. 


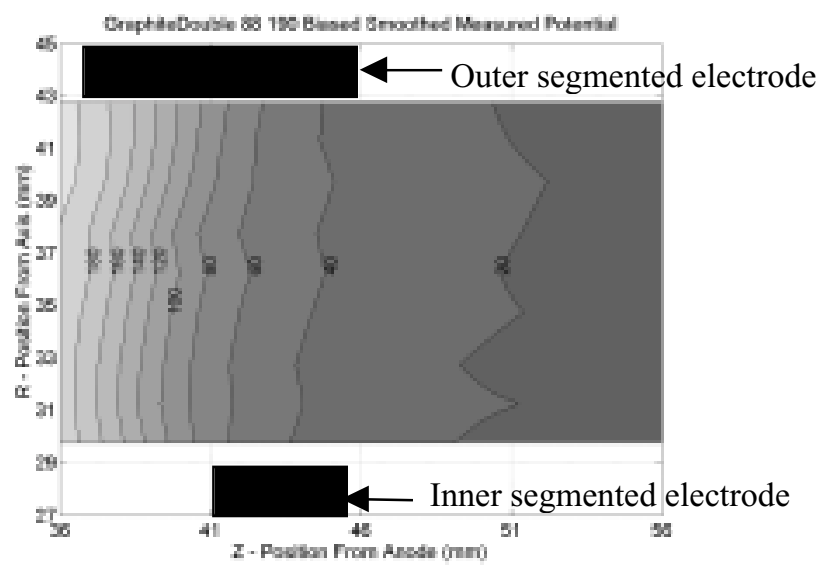

Figure 10: Plasma potential distribution measured for two-segmented thruster configuration. An additional $8 \mathrm{~mm}$ length segmented electrode is placed on the outer wall near the exit opposite to the inner segmented electrode.

The channel exit at $46 \mathrm{~mm}$. The inner wall at $R_{i n}=27 \mathrm{~mm}$ and outer wall at $R_{o t}=45 \mathrm{~mm}$. 


\section{External Distribution}

Plasma Research Laboratory, Australian National University, Australia

Professor I.R. J ones, Flinders University, Australia

Professor J oão Canalle, Instituto de Fisica DEQ/IF - UERJ , Brazil

Mr. Gerson O. Ludwig, Instituto Nacional de Pesquisas, Brazil

Dr. P.H. Sakanaka, Instituto Fisica, Brazil

The Librarian, Culham Laboratory, England

Library, R61, Rutherford Appleton Laboratory, England

Mrs. S.A. Hutchinson, JET Library, England

Professor M.N. Bussac, Ecole Polytechnique, France

Librarian, Max-Planck-Institut für Plasmaphysik, Germany

J olan Moldvai, Reports Library, MTA KFKI-ATKI, Hungary

Dr. P. Kaw, Institute for Plasma Research, India

Ms. P.J . Pathak, Librarian, Insitute for Plasma Research, India

Ms. Clelia De Palo, Associazione EURATOM-ENEA, I taly

Dr. G. Grosso, Instituto di Fisica del Plasma, Italy

Librarian, Naka Fusion Research Establishment, J AERI, J apan

Library, Plasma Physics Laboratory, Kyoto University, J apan

Research Information Center, National Institute for Fusion Science, J apan

Dr. O. Mitarai, Kyushu Tokai University, J apan

Library, Academia Sinica, Institute of Plasma Physics, People's Republic of China

Shih-Tung Tsai, Institute of Physics, Chinese Academy of Sciences, People's Republic of China

Dr. S. Mirnov, TRINITI, Troitsk, Russian Federation, Russia

Dr. V.S. Strelkov, Kurchatov Institute, Russian Federation, Russia

Professor Peter Lukac, Katedra Fyziky Plazmy MFF UK, Mlynska dolina F-2, Komenskeho Univerzita, SK-842 15 Bratislava, Slovakia

Dr. G.S. Lee, Korea Basic Science Institute, South Korea

Mr. Dennis Bruggink, Fusion Library, University of Wisconsin, USA

Institute for Plasma Research, University of Maryland, USA

Librarian, Fusion Energy Division, Oak Ridge National Laboratory, USA

Librarian, Institute of Fusion Studies, University of Texas, USA

Librarian, Magnetic Fusion Program, Lawrence Livermore National Laboratory, USA

Library, General Atomics, USA

Plasma Physics Group, Fusion Energy Research Program, University of California at San Diego, USA

Plasma Physics Library, Columbia University, USA

Alkesh Punjabi, Center for Fusion Research and Training, Hampton University, USA

Dr. W.M. Stacey, Fusion Research Center, Georgia Institute of Technology, USA

Dr. J ohn Willis, U.S. Department of Energy, Office of Fusion Energy Sciences, USA

Mr. Paul H. Wright, Indianapolis, Indiana, USA 
The Princeton Plasma Physics Laboratory is operated by Princeton University under contract with the U.S. Department of Energy.

\author{
Information Services \\ Princeton Plasma Physics Laboratory \\ P.O. Box 451 \\ Princeton, NJ 08543
}

Phone: 609-243-2750

Fax: 609-243-2751

e-mail: pppl_info@pppl.gov

Internet Address: http://www.pppl.gov 